\title{
Hot Deformation Behavior and Hardness of a CoCrFeMnNi High-Entropy Alloy with High Content of Carbon
}

\author{
Yi-Tao Wang ${ }^{1} \cdot$ Jian-Bo Li ${ }^{1} \cdot$ Yun-Chang Xin ${ }^{2} \cdot$ Xian-Hua Chen ${ }^{1} \cdot$ Muhammad Rashad $^{3} \cdot$ Bin Liu $^{4} \cdot$ Yong Liu $^{4}$
}

Received: 21 January 2019 / Revised: 25 March 2019 / Published online: 27 May 2019

(c) The Chinese Society for Metals (CSM) and Springer-Verlag GmbH Germany, part of Springer Nature 2019

\begin{abstract}
A CoCrFeMnNi high-entropy alloy with a high content of carbon was synthesized, and its hot deformation behavior was studied at the temperatures $800-1000{ }^{\circ} \mathrm{C}$ at the strain rates ranging from 0.001 to $0.1 \mathrm{~s}^{-1}$. As-prepared alloy is a face-centered cubic-structured solid solution, with a large amount of carbides residing at grain boundaries. True stress-strain curves were employed to develop the constitutive equation of apparent activation energy. The apparent activation energy $(Q)$ was found to be $423 \mathrm{~kJ} \mathrm{~mol}^{-1}$, indicating a dynamic flow softening behavior. The size of dynamic recrystallized (DRXed) grains increases with increasing the temperature or decreasing the strain rate. A processing map was sketched on the basis of the flow stress. The temperature range of $900-1000^{\circ} \mathrm{C}$ and $10^{-3}-10^{-2.6} \mathrm{~s}^{-1}$ strain rate were found to be the optimum hot-forging parameter. With increasing temperature or decreasing strain rate, the volume fraction of fine carbides $(\leq 1 \mu \mathrm{m})$ increases. A lot of coarse carbides can be found in the matrix after deformation at $800^{\circ} \mathrm{C}$, which leads to a high hardness value of $345 \mathrm{HV}$. The carbides after deformation at $1000{ }^{\circ} \mathrm{C}$ are mainly nano-sized $M_{7} \mathrm{C}_{3}$ and $M_{23} \mathrm{C}_{6}$, which can promote the nucleation of DRX.
\end{abstract}

Keywords High-entropy alloy $\cdot$ Carbon · Apparent activation energy $\cdot$ Processing map $\cdot$ Dynamic recrystallization

\section{Introduction}

Tool steel materials are widely used in the fields of molds, cutting tools and rolls, which have high strength, hardness and wear resistance but the low plasticity and poor fracture toughness, leading to the reduction in service life $[1,2]$. With the development of materials science, the impasse is

Available online at http://link.springer.com/journal/40195

Jian-Bo Li

lijianbo1202@cqu.edu.cn

$\triangle$ Yun-Chang Xin

ycxin@cqu.edu.cn

1 School of Materials Science and Engineering, Chongqing University, Chongqing 400044, China

2 International Joint Laboratory for Light Alloys, College of Materials Science and Engineering, Chongqing University, Chongqing 400030, China

3 School of Materials Science and Engineering, Jiangsu University of Science and Technology, Zhenjiang 212003, China

4 State Key Laboratory of Powder Metallurgy, Central South University, Changsha 410083, China expected to be broken. Yeh et al. [3-5] proposed a novel system called high-entropy alloys (HEAs). The HEAs contain five or more elements in equiatomic or nearly, but the crystal structures tend to be single-phased solid solution [6]. HEAs have received much attention for their unique structures and excellent mechanical properties, such as excellent cryogenic strength and toughness [7-9], good corrosion resistance [10], good irradiation resistance [11] and excellent thermal stability [12]. Among various HEAs, $\mathrm{CoCrFeMnNi}$ (fcc) has been widely studied due to its extremely high fracture toughness at room and cryogenic temperatures (217-219 $\mathrm{MPa} \bullet \mathrm{m}^{1 / 2}$ ) [13]. Moreover, the ultrafine-grained CoCrFeMnNi HEA possesses high fatigue strength (280 MPa) [14]. However, the hardness of CoCrFeMnNi HEA with refined crystalline strengthening remains difficult to meet the requirements of tool steel. Alloying provides a significant effect on the microstructure and mechanical properties of HEAs $[15,16]$. On the basis of high-entropy alloy composition, tooling materials with high hardness and toughness can be developed through precipitation strengthening. The strengthening $\mathrm{CoCrFeMnNi} \mathrm{HEA} \mathrm{can} \mathrm{be} \mathrm{considered} \mathrm{as} \mathrm{a} \mathrm{potential}$ candidate for tooling materials application.

Notably, the mechanical behavior of $\mathrm{CoCrFeMnNi}$ alloy is similar to that of austenitic steel (TWIP steels) [17]. In 
general, $\mathrm{C}$ and $\mathrm{Si}$ are frequently added into TWIP steels, as the interstitial atoms can obtain outstanding mechanical properties due to reduction of grain size and triggering nano-twinning $[18,19]$. At present, many researchers have reported that the hardness and strength of HEAs can be improved by carbon addition $[20,21]$. The solution strengthening and formation of hard carbide phase have been reported as the main contributions to the improvement of the hardness and wear resistance of $\mathrm{CoCrFeNiC}_{X}$ HEA [22]. For $\mathrm{CoCrFeMnNi} \mathrm{HEA,} \mathrm{the} \mathrm{carbon} \mathrm{addition} \mathrm{can} \mathrm{enhance} \mathrm{its}$ strength [23, 24]. In the meantime, the Vickers hardness of heavy carbon-alloyed $\mathrm{Fe}_{40} \mathrm{Mn}_{40} \mathrm{Co}_{10} \mathrm{Cr}_{10}$ can reach as high as $400 \mathrm{HV}$, when a carbon content of 8.9 at.\% was added in the matrix, due to a high-content interstitial carbon atoms [25]. Compared with AISI D3 cold work tool steel ( $350 \mathrm{HV})$, the hardness of carbon-contenting CoCrFeMnNi HEAs can be a competent in industrial demand, which has a longer service life [26, 27]. Though carbide with high hardness and hightemperature stability is an important strengthening phase in wear-resistant materials [28], carbide-reinforced HEAs are difficult to shape due to the very limited macroscopic deformation ability at room temperature.

Hot working is regarded as an effective way to improve the microstructure and mechanical performance [29], which can avoid casting defects such as segregation, coarse grains and shrinkage holes. Also, a processing map is an effective method to determine the optimum working conditions. In the meantime, hot deformation can promote the formation of the precipitated phases, and a possible governing mechanism can be obtained [30]. Therefore, the heavy carbon addition into $\mathrm{CoCrFeMnNi} \mathrm{HEA} \mathrm{may} \mathrm{result} \mathrm{in} \mathrm{both} \mathrm{high} \mathrm{hardness}$ and relatively suitable hot workability and thus is valuable to explore.

In this study, the thermal deformation behavior of a $(\mathrm{CoCrFeMnNi})_{95} \mathrm{C}_{5}$ (at.\%) alloy at the temperatures range from 800 to $1000{ }^{\circ} \mathrm{C}$ and strain rates from 0.001 to $0.1 \mathrm{~s}^{-1}$ was systematically investigated. The relation between flow behavior and microstructural evolution was addressed, and a processing map for the isothermal compression was constructed. An optimum hot deformation condition $\left(800{ }^{\circ} \mathrm{C} / 10^{-1} \mathrm{~s}^{-1}\right)$ was found for $(\mathrm{CoCrFeMnNi}){ }_{95} \mathrm{C}_{5}$ alloy, to achieve the highest hardness for tool steel applications. The deformation mechanism for dynamic recrystallization is also discussed.

\section{Experimental}

The alloy with a nominal composition of $(\mathrm{CoCrFeMnNi}){ }_{95} \mathrm{C}_{5}$ (at.\%) was prepared by arc-melting of elements in a lowpressure, high-purity argon atmosphere inside a water-cooled copper mold. The purities of the alloying elements were above 99.9 at.\%. Carbon was added in a form of $\mathrm{Cr}_{3} \mathrm{C}_{2}$ block to avoid being blown away. In order to improve the chemical homogeneity, all samples were flipped over and re-melted at least 5 times. The actual concentration of carbon in the alloy was measured with LECO analyzer, and the results show that the actual carbon concentration is within \pm 0.1 at. $\%$ of the nominal carbon. The produced ingots had a dimension of about $\phi 40 \mathrm{~mm} \times 20 \mathrm{~mm}$. The ingots were homogenized at $800{ }^{\circ} \mathrm{C}$ for $24 \mathrm{~h}$ and then air-cooled. The compression samples $(\varphi 8 \mathrm{~mm} \times 12 \mathrm{~mm})$ were cut down by electric discharge machine. The compression tests were conducted at the temperatures of $800{ }^{\circ} \mathrm{C}$ and $1000{ }^{\circ} \mathrm{C}$ at strain rates from 0.001 to $0.1 \mathrm{~s}^{-1}$ on a Gleeble- 3180 thermo-mechanical simulator. The samples were heated using a fixed heating speed of $5{ }^{\circ} \mathrm{C} / \mathrm{s}$ and homogenized for $5 \mathrm{~min}$ at the deformation temperature and then deformed with the maximum nominal reduction of $60 \%$. Finally, the samples were quenched to room temperature to preserve the deformation microstructure.

Microstructures of the initial material and compressed specimens were characterized by X-ray diffraction (XRD), scanning electron microscopy (SEM), optical microscopy $(\mathrm{OM})$, electron backscatter diffraction (EBSD) and transmission electron microscopy (TEM). XRD analysis was performed using an ARL-X-tra diffractometer with $\mathrm{CuK \alpha}$ radiation at $45 \mathrm{kV}$ and $35 \mathrm{~mA}$ at a scan rate of $2 \% \mathrm{~min}$ from $30^{\circ}$ to $90^{\circ}$. The samples for SEM, OM and EBSD analysis were prepared by electropolishing, in a mixture of $5 \%$ perchloric acid and $95 \%$ alcohol with $27 \mathrm{~V}$ potential at room temperature. SEM images were taken using field emission gun scanning electron microscope (FEI NanoSEM 400) at an accelerated voltage of $20 \mathrm{kV}$. OM images were obtained with an optical microscope (Axio Visio, Carl Zeiss). EBSD was performed by electron microscope (TESCAN MIRA3) with a scan step of $0.15 \mu \mathrm{m}$. The AzTec HKL software (Oxford Instruments) was used for the data acquisition. Samples for TEM analysis were prepared by double-jet electro-polishing of $5 \%$ perchloric acid and $95 \%$ alcohol at the $27 \mathrm{~V}$ with a temperature of $-30^{\circ} \mathrm{C}$. TEM analysis was performed using a JEOL-2100F microscope at a voltage of $200 \mathrm{kV}$.

A 500-g load under $12 \mathrm{~s}$ was used in Vickers hardness tests by Vickers hardness testing machine (HMV-G 20ST). Each test was repeated at least six times. The hardness of quenched samples was tested at room temperature, and each test was repeated at least six times.

\section{Results}

\subsection{Initial Microstructure of the (CoCrFeMnNi) ${ }_{95} \mathrm{C}_{5}$ (at.\%) Alloy}

Figure 1 presents the initial microstructure of $(\mathrm{CoCrFeMnNi}){ }_{95} \mathrm{C}_{5}$ (at.\%) HEA, which shows an inhomogeneous microstructure and a grain size of about $50 \mu \mathrm{m}$. Many 

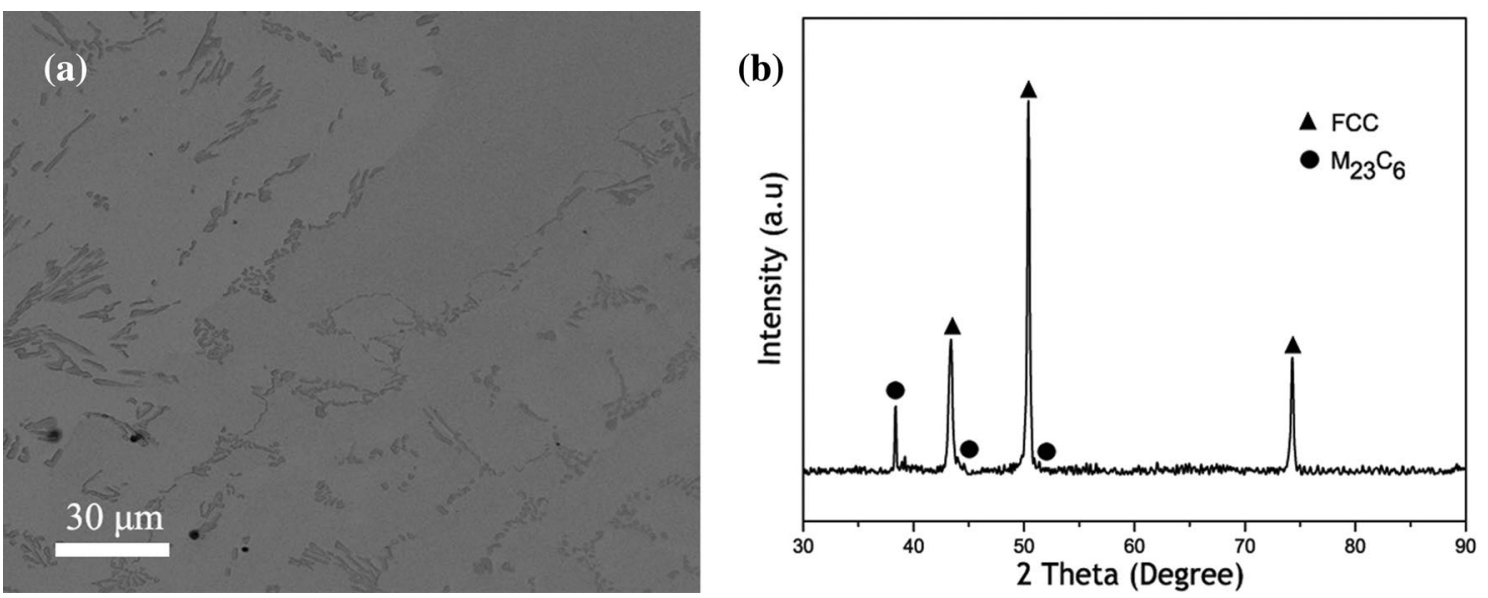

Fig. 1 Structure of the $(\mathrm{CoCrFeMnNi}){ }_{95} \mathrm{C}_{5}$ (at.\%) alloy at the initial homogenized condition: a SEM-BSE image, $\mathbf{b}$ X-ray diffraction pattern

elongated shaped grains were likely formed during solidification, and many precipitate particles appear at the grain boundaries. Meanwhile, the dark points shown in Fig. 1a are manganese oxide particles, which had been reported by a previous publication [31]. The XRD analysis (Fig. 1b) confirms that the alloy was mainly composed of fcc phase and $M_{23} \mathrm{C}_{6}$ precipitates, and the manganese oxide particles are not traced due to its relatively low content.

\subsection{Flow Behaviors}

The flow curves were measured at the temperature range from 800 to $1000{ }^{\circ} \mathrm{C}$ and the strain rate range from $10^{-3}$ to $10^{-1} \mathrm{~s}^{-1}$, as shown in Fig. 2. It can be found that the flow stress decreases with increasing deformation temperature and decreasing strain rate. The flow curves exhibit an initial hardening until a peak stress followed by a gradual softening and finally reach a steady stage. When the temperature is high enough, the flow stress obtained at $100{ }^{\circ} \mathrm{C}$ is nearly not affected by the strain rate, as shown in Fig. 2b, c. The characteristic shapes of the flow curves indicate that a dynamic recrystallization process occur during hot deformation. In order to study the microstructure evolution at different deformation conditions, representative microstructures are illustrated in later part.

\subsection{Constitutive Equation}

The flow behavior during hot deformation can be considered as a thermal activation process; thus, the flow stress was analyzed by using the Arrhenius-type hyperbolic sinusoidal relationship, which was originally reported by Zener [32].

$Z=\dot{\varepsilon} \exp \left(\frac{Q}{R T}\right)=A[\sinh (\alpha \sigma)]^{n}$,

where $Z$ is the Zener-Hollomon parameter, $\dot{\varepsilon}$ is the strain rate, $A, n$ and $\alpha$ are material constants, $\sigma$ is the peak or steady of flow stress, $Q$ is the activation energy corresponding to the deformation mechanism in the thermal process, $R$ is gas constant $(=8.314 \mathrm{~J} / \mathrm{mol} \mathrm{K})$, and $T$ is the deformation temperature in Kelvin. The $Q$ value can be calculated by using the transformation of Eq. (2):

$Q=R\{\partial \ln \dot{\varepsilon} / \partial \ln [\sinh (\alpha \sigma)]\}_{T}\{\partial \ln [\sinh (\alpha \sigma)] / \partial(1 / T)\}_{\dot{\varepsilon}}$.
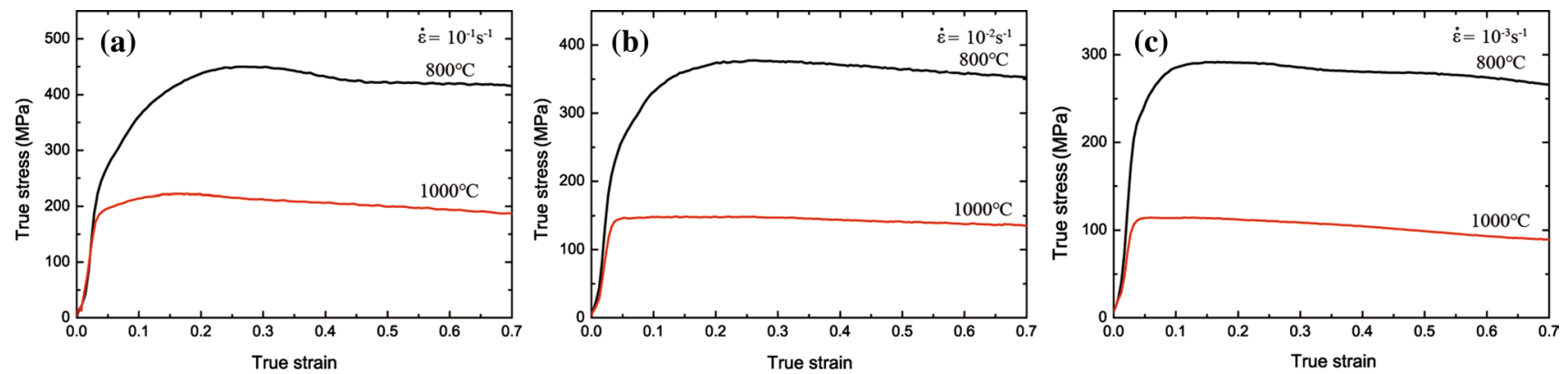

Fig. 2 Stress-strain curves at various deformation temperatures and strain rates of a $10^{-1} \mathrm{~s}^{-1}, \mathbf{b} 10^{-2} \mathrm{~s}^{-1}, \mathbf{c} 10^{-3} \mathrm{~s}^{-1}$ 


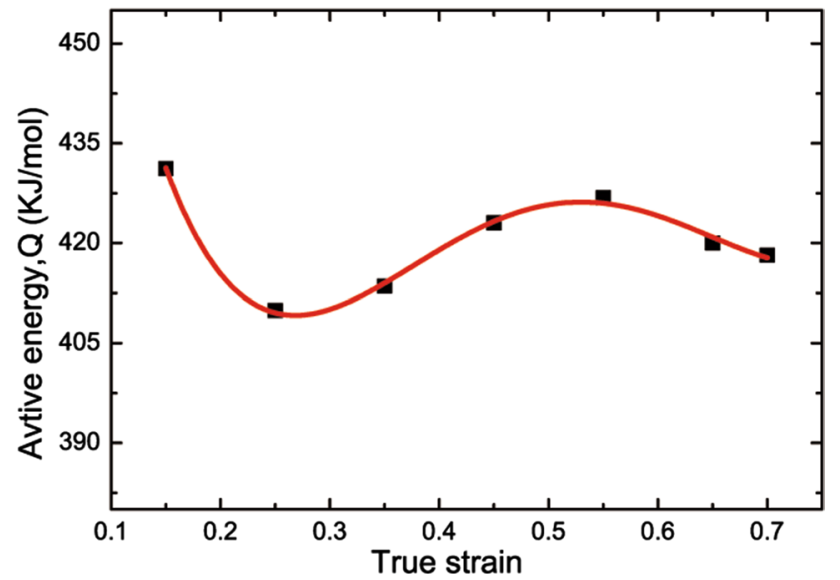

Fig. 3 Variation of activation energy $(Q)$ with true strain

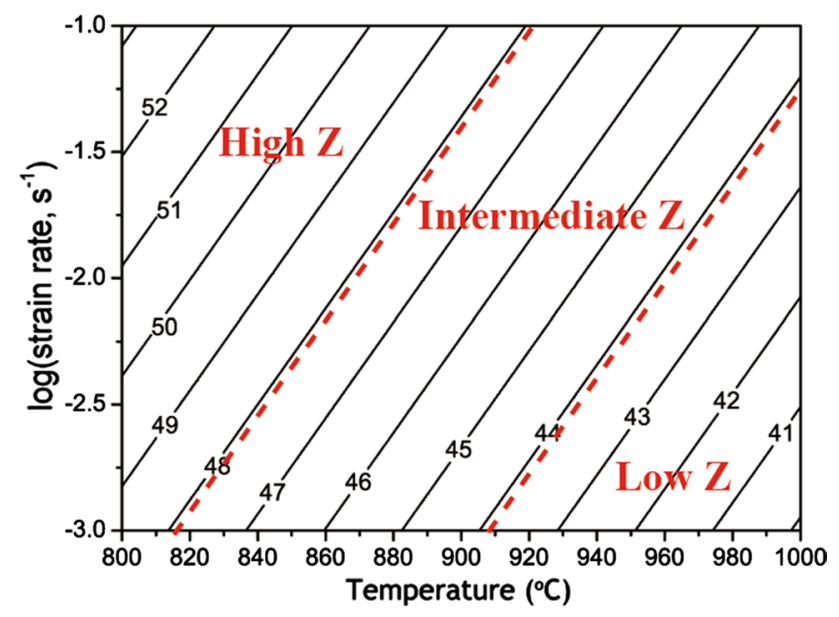

Fig. 4 Zener-Hollomon parameter of $\left(\mathrm{CoCrFeMnNi}{ }_{95} \mathrm{C}_{5}\right.$ (at.\%) HEA as a function of strain rate and temperature. The values on the contour lines are $\ln Z$

The value of $Q$ at the strain of 0.45 is estimated as $423.1 \mathrm{~kJ} / \mathrm{mol}$. A hyperbolic sine-type equation that describes the dependence of the stress on the $T$ and $\dot{\varepsilon}$ can be written as:

$\dot{\varepsilon}=3.46 \times 10^{19}[\sinh (0.0044 \sigma)]^{6.95} \exp (-423.1 / 8.314 \times T)$.

The values of $Q$ at different strains were also estimated by a similar way and are shown in Fig. 3. The result demonstrates that the value of $Q$ is a little higher at initial deformation stage, and then, it nearly reaches a steady state as the deformation strain increases, which is of about $423 \mathrm{~kJ} / \mathrm{mol}$.

Figure 4 indicates the Zener-Hollomon parameter during the thermal deformation of the present $(\mathrm{CoCrFeMnNi}){ }_{95} \mathrm{C}_{5}$ (at.\%) HEA alloy. The Zener-Hollomon parameter is calculated by Eq. (1) based on the flow stress data. It can be found that decreasing the temperature and increasing the strain rate can result in an increase in Zener-Hollomon parameter. This map contains three domains: high $Z$ domain $(\ln Z \leq 48.0)$, intermediate $Z$ domain $(44.0 \leq \ln Z<48.0)$ and low $Z$ domain $(\ln Z<44.0)$.

\subsection{Processing Map}

In recent years, based on the dynamic materials model (DMM), a processing map has been developed to confirm the optimum processing conditions. Briefly, the workpiece during hot deformation is considered as a dissipater of power. During hot deformation, the power can be partitioned by the strain rate sensitivity $(m)$ into two parts: (1) the power corresponding to the deformation heat and (2) the microstructural evolutions. The characteristics of the power dissipation occurring through microstructural changes during deformation can be expressed by the efficiency of power dissipation $(\eta)$, shown as [33]:

$\eta=\frac{2 m}{m+1}$,

where $m$ is the strain rate-sensitive parameter of the material. The power dissipation map is formed by the variation of $\eta$ at different deformation temperatures and strain rates, which determine the characteristic areas of damage processes and various hot deformations. In addition, based on an instability equation, an instable map can be received by a dimensionless instability parameter, which was given by Ziegler's criteria [33]:

$\xi(\dot{\varepsilon})=\frac{\partial \ln [m /(m+1)]}{\partial \ln \dot{\varepsilon}}+m<0$.

Figure 5 shows the processing map of the $(\mathrm{CoCrFe}$ $\mathrm{MnNi}$ ) ${ }_{95} \mathrm{C}_{5}$ (at.\%) HEA obtained at a true strain 0.65 (steady state). At the top corner, the flow instability appears at a strain rate higher than $10^{-2.4} \mathrm{~s}^{-1}$, with a temperature range of $800-1000^{\circ} \mathrm{C}$ (Domain 1 , high $Z$ area). It is clear that the value of $\eta$ (less than 28\%) in this region (Fig. 5a) suggests a weak workability. In contrast, there is a relatively highefficiency region (close to 30\%) in the bottom right corner with the strain rate range of $10^{-3}-10^{-2.6} \mathrm{~s}^{-1}$ and the temperature range of $900-1000^{\circ} \mathrm{C}$ (Domain 2, intermediate and low $Z$ area). Since there is little information on processing map of carbon-containing CoCrFeMnNi HEAs, we have to refer to some other alloys. Generally, the value of $\eta$ (approximate $30 \%$ ) is related to dynamic recrystallization (DRX) [34]. In our study, a peak $\eta$ of $33 \%$ is obtained at $1000{ }^{\circ} \mathrm{C}$ with a strain rate of $10^{-3} \mathrm{~s}^{-1}$, indicating that dynamic recrystallization may happen during the hot deformation in Domain 2. Therefore, Domain 2 in Fig. 5a can be suggested to be the optimum hot-working condition. Figure $5 \mathrm{~b}$ shows the microstructure deformed at high $Z$ condition $(\ln Z=53.19$, $\left.800{ }^{\circ} \mathrm{C} / 10^{-1} \mathrm{~s}^{-1}\right)$, which is located in flow instability region, 

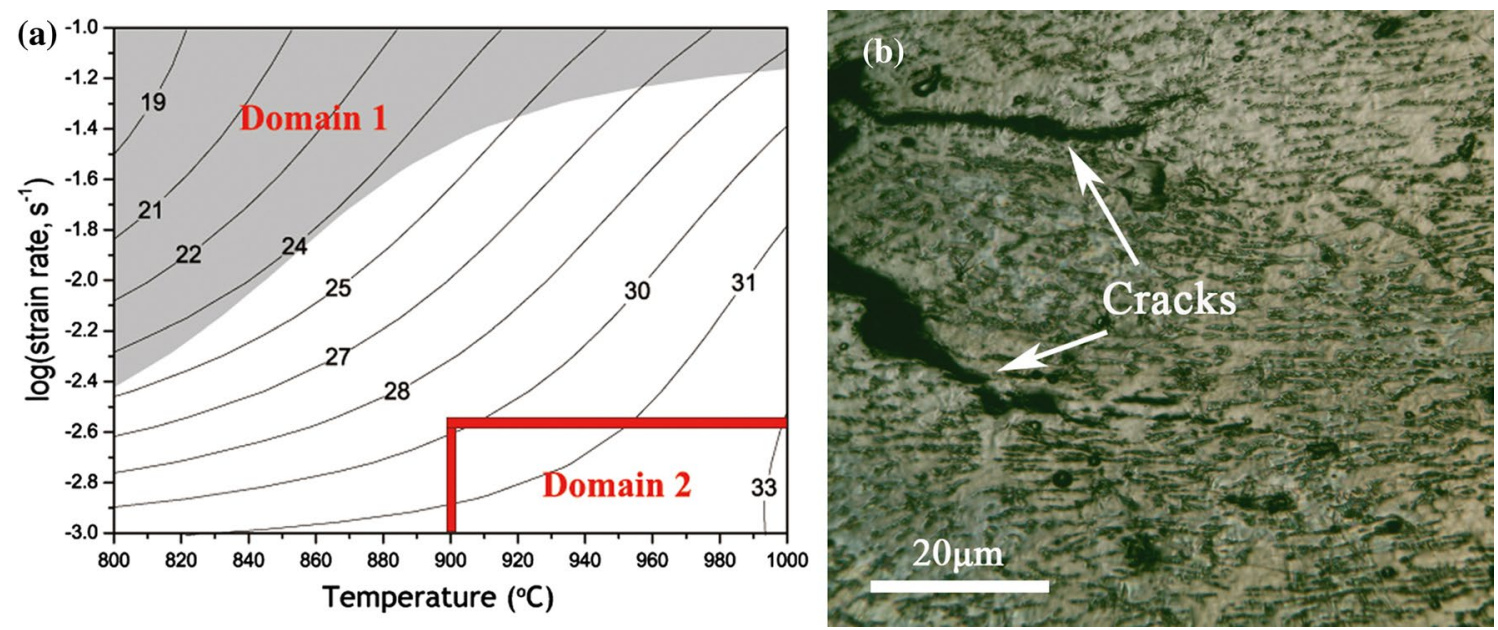

Fig. 5 a Processing map at a true strain of 0.65 , $\mathbf{b}$ optical micrograph showing the cracking at the edge of the specimen which was deformed at $\ln Z=53.19\left(\right.$ high $\left.Z, 800{ }^{\circ} \mathrm{C} / 10^{-1} \mathrm{~s}^{-1}\right)$

and the cracks appearing at the edge of the specimen can validate the processing map.

\subsection{Microstructure Characterization}

Figure 6 shows SEM micrographs of $(\mathrm{CoCrFeMnNi})_{95} \mathrm{C}_{5}$ (at.\%) HEA alloy deformed at various $Z$ conditions. As shown in Fig. 6a, the coarse particles at the grain boundaries with a size of about $2-5 \mu \mathrm{m}$ and a volume fraction of $12.14 \%$ have broken up, and there are no fine precipitates inside the grains. All of the volume fractions are measured by the contrast adjustment function in Image-Pro Plus. Some voids can be observed at the particles/matrix interphase when the specimen is deformed at comparatively high $Z$ value $(\ln Z=53.19)$. As the $Z$ value decreases, the volume fraction of coarse particles decreases to $10.44 \%$ and a few fine particles $(\leq 1 \mu \mathrm{m})$ appear, with a volume fraction of $4.12 \%$ (Fig. 6b). When the specimen is deformed at a lower $Z$ value, the volume fraction of coarse particles decreases to $6.48 \%$, but the volume fraction of fine particles increases to $6.44 \%$ (Fig. 6c). As $\ln Z$ decreases to the lowest value (39.88), the homogeneity of deformed structure is obviously improved. The volume fraction of coarse particles decreases to the lowest value (3.09\%), while the volume fraction of fine particles increases to the maximum value of about $7.14 \%$ (Fig. 6d).

Figure 7 presents the XRD pattern of the $(\mathrm{CoCrFeMnNi})_{95} \mathrm{C}_{5}$ (at.\%) alloys at different $Z$ values. Compared with Fig. 1b, there is no difference between the phase composition of the alloy deformed at high $Z$ values and that of initial alloy. The diffraction patterns show the peaks from fcc phase and $M_{23} \mathrm{C}_{6}$-type precipitates, indicating that the coarse particles are coarse carbides. However, decreasing intensity of $M_{23} \mathrm{C}_{6}$ with a cubic structure indicates a decrease in the content of coarse carbides. When the alloy is deformed at low $Z$ value, tiny peaks of $M_{7} C_{3}$ carbides with orthorhombic structures appear at diffraction locations; thus, the carbides in the microstructure deformed at low $Z$ value are composed of $M_{7} \mathrm{C}_{3}$ and $M_{23} \mathrm{C}_{6}$ carbides.

Additionally, the distribution of elements in $(\mathrm{CoCrFeMnNi}){ }_{95} \mathrm{C}_{5}$ (at.\%) alloy deformed at low $Z$ condition $\left(\ln Z=39.88,1000^{\circ} \mathrm{C} / 10^{-3} \mathrm{~s}^{-1}\right)$ was conducted by TEM combined with EDS in the STEM mode. The maps of the element distributions in the area marked by a rectangular frame in Fig. 8a confirmed the inhomogeneous distribution of $\mathrm{Cr}$ (Fig. 8b) and C (Fig. 8g). Combined with the analysis above, it can be determined that the Cr-enrich particles with a small quantity of Mn elements are $M_{23} \mathrm{C}_{6}$ and $M_{7} \mathrm{C}_{3}$ carbides.

Figure 9 shows EBSD inverse pole figure (IPF) maps and image quality (IQ) maps of the resulting microstructures at different deformation conditions. Low-angle grain boundaries (LAGBs) $\left(2^{\circ}<\theta<15^{\circ}\right)$ are marked by red lines and high-angle grain boundaries (HAGBs) $\left(\theta \geq 15^{\circ}\right)$ by black lines. The microstructure of deformed alloy is highly dependent on $Z$ value. At high $Z$ values, the grains are elongated in the direction perpendicular to the compression axis, and some fine DRX grains can be found near the grain boundaries (Fig. 9a). The low-angle grain boundaries appear mainly near the initial grain boundaries where severe deformation may happen, with a fraction of $21 \%$ (Fig. 9b). With a low $Z$ value, more fine DRX grains appear at the grain boundaries (Fig. 9c), which results in the formation of recrystallized structure so-called necklace structure and the fraction of LAGBs decreased to 13\% (Fig. 9d). Further decrease in $Z$ value results in an increase in recrystallized grain size and fraction, the LAGBs mainly locate within initial grains with a fraction of 5\% (Fig. 9e, f). 

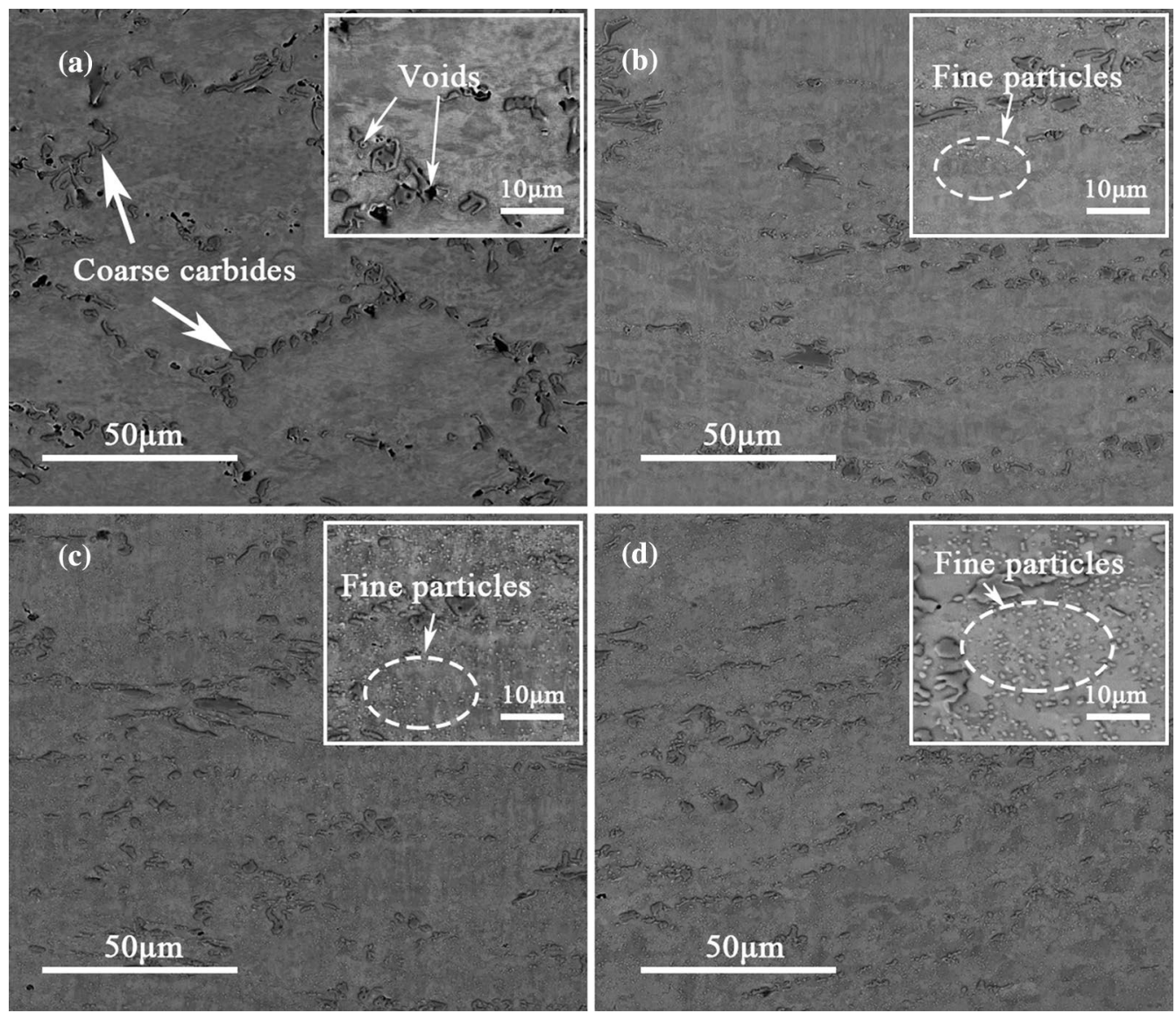

Fig. $6 \mathrm{SEM}$ micrographs of specimens deformed at a $\ln Z=53.19$ (high $Z, 800{ }^{\circ} \mathrm{C} / 10^{-1} \mathrm{~s}^{-1}$ ), b $\ln Z=48.59\left(\right.$ high $Z, 800{ }^{\circ} \mathrm{C} / 10^{-3} \mathrm{~s}^{-1}$ ), c $\ln Z=44.48$ (intermediate $Z, 1000{ }^{\circ} \mathrm{C} / 10^{-1} \mathrm{~s}^{-1}$ ), $\mathbf{d} \ln Z=39.88$ (low $Z, 1000{ }^{\circ} \mathrm{C} / 10^{-3} \mathrm{~s}^{-1}$ ). The volume fractions of coarse particles are a $12.14 \%$, b $10.44 \%$, c $6.48 \%$, d $3.09 \%$, while the volume fractions of fine particles are a $0 \%$, b $4.12 \%$, c $6.44 \%$, d $7.14 \%$, respectively

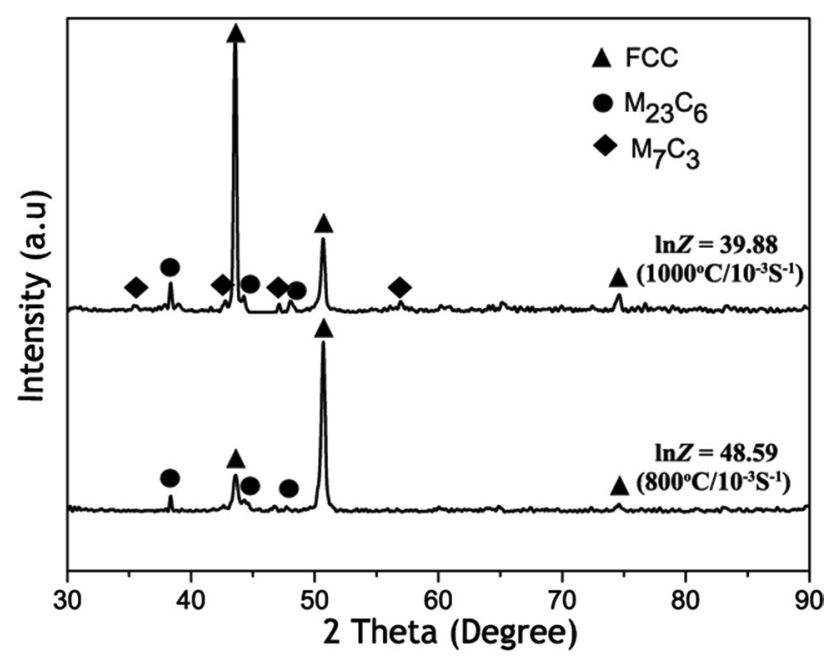

Fig. 7 XRD patterns of the $(\mathrm{CoCrFeMnNi})_{95} \mathrm{C}_{5}$ (at.\%) alloy in the different conditions of $Z$ value. $\ln Z=48.59$ (high $Z, 800{ }^{\circ} \mathrm{C} / 10^{-3} \mathrm{~s}^{-1}$ ) and $\ln Z=39.88\left(\right.$ low $\left.Z, 1000^{\circ} \mathrm{C} / 10^{-3} \mathrm{~s}^{-1}\right)$
Further insights into microstructures deformed at different $Z$ conditions were obtained by TEM operation (Fig. 10). It was found that when the specimen is deformed at high $Z$ condition, a large number of square particles with average size of $250 \pm 20 \mathrm{~nm}$ distribute uniformly in the deformed microstructure, and the particles correspond to $M_{23} \mathrm{C}_{6}$ carbide with a cubic structure as shown in Fig. 10a, while, at low $Z$ condition, there are a lot of elliptical nanoparticles with average longitudinal and transversal size of $150 \pm 20 \mathrm{~nm}$ and $50 \pm 10 \mathrm{~nm}$, respectively, which may refer to the mixture of $M_{23} \mathrm{C}_{6}$ and $M_{7} \mathrm{C}_{3}$ carbides (Fig. 10b). The extensive cross-slip produces irregular dislocation cells around the carbides as shown in Fig. 10c, leading to the formation of subgrain. Recrystallized (DRX) grain at the vicinity of carbides particles is observed, as shown in Fig. 10d, and revealed that the recrystallization usually begins with dynamic recovery, and then, a process of the rearrangement of dislocations follows to form a low energy configuration. 


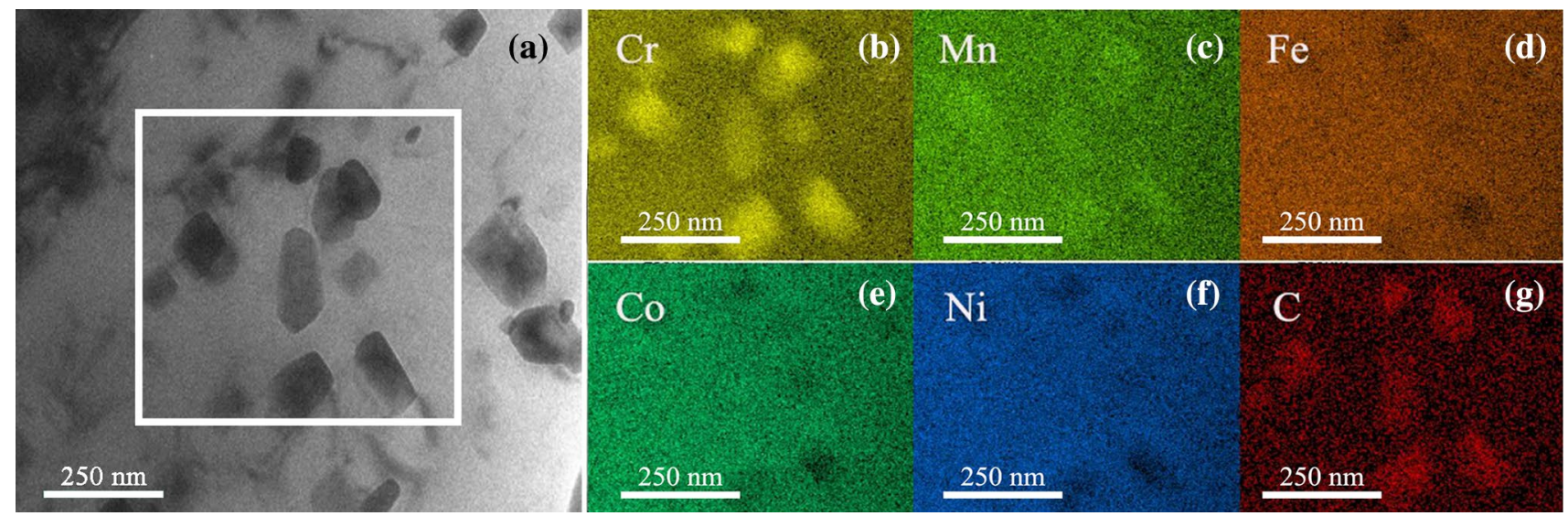

Fig. 8 STEM image of $(\mathrm{CoCrFeMnNi})_{95} \mathrm{C}_{5}$ (at.\%) alloy deformed at $\ln Z=39.88$ (low $\mathrm{Z}, 1000{ }^{\circ} \mathrm{C} / 10^{-3} \mathrm{~s}^{-1}$ ) a, distributions of alloy constituents: b $\mathrm{Cr}, \mathbf{c} \mathrm{Mn}, \mathbf{d} \mathrm{Fe}$, e Co, f Ni, g C

\subsection{Hardness of the $(\mathrm{CoCrFeMnNi})_{95} \mathrm{C}_{5}$ (at.\%) Alloy}

The hardness of the hot-deformed alloys tested at the room temperature is shown in Fig. 11a. Generally, the hardness of $(\mathrm{CoCrFeMnNi}){ }_{95} \mathrm{C}_{5}$ (at.\%) alloy deformed at $800{ }^{\circ} \mathrm{C}$ is a little higher than that of HEA deformed at $1000^{\circ} \mathrm{C}$. When the specimens were deformed at $800{ }^{\circ} \mathrm{C}$, the hardness increases from $300 \mathrm{HV}$ to $345 \mathrm{HV}$ with strain rate increasing; however, the hardness remains constant with a value about $285 \mathrm{HV}$ when deformed at $1000{ }^{\circ} \mathrm{C}$. The relationship between the hardness of the deformed alloys and $Z$ parameter is shown in Fig. $11 \mathrm{~b}$. The hardness increases with increasing $Z$ value, and the curve indicates a linear dependence relationship. The comparison of microhardness of $\mathrm{CoCrFeNi}$-based alloys fabricated by different processing methods is shown in Table 1. It can be seen that the hardness of $(\mathrm{CoCrFeMnNi}){ }_{95} \mathrm{C}_{5}$ (at.\%) alloy deformed at $800{ }^{\circ} \mathrm{C} / 10^{-1} \mathrm{~s}^{-1}$ is significantly higher than those of other arc-melting (AM) alloys [35, 36], but is lower than those of CoCrFeNiMn alloy fabricated by mechanical alloying (MA) and spark plasma sintering (SPS). This may be due to the fact that the CoCrFeNiMn alloy fabricated by MA and SPS exhibited nano-scale grains and coexistence of BCC phase and FCC phase [37, 38]. However, the MA and SPS techniques are timeconsuming, and the complex process may cause a higher cost. Therefore, it is difficult to meet the requirements for industrial production. From such considerations, the hardness of $\mathrm{CoCr}$ FeMnNi-based alloys was greatly affected by high content of carbon addition and deformation condition.

\section{Discussion}

\subsection{Activation Energy (Q)}

Activation energy is reported to be sensitive to the composition of alloys, reflecting the workability of alloys [39]. The comparison of the activation energies $Q$ of $\mathrm{CoCr}$ FeMnNi-based alloys is summarized in Table 2. It can be found that the thermal deformation activation energy $(423 \mathrm{~kJ} / \mathrm{mol})$ obtained for $(\mathrm{CoCrFeMnNi})_{95} \mathrm{C}_{5}$ (at.\%) alloy is higher than that of other $\mathrm{CoCrFeMnNi}$-based alloys [40]. The relatively higher $Q$ for the present alloy may result from an addition of a high content of carbon. The high content of carbon will lead to both solid-solution hardening and precipitation hardening; thus, cross-slip of dislocations is effectively hindered [41]. Besides, DRX process can be regarded as a process of element migration. However, the high content of carbon can distort the fcc lattice leading to a more difficult element migration. This phenomenon has also been noticed by Wang et al. [42]. As a result, the DRX process may need more energy. At the same time, the incompatibility of deformation will result in high internal stresses, which will reduce the deformability and lead to more microcracks appear at their interfaces in the alloy. Thus, incompatibility of deformation also accounts for the high activation energy, as shown in Fig. 5b. 

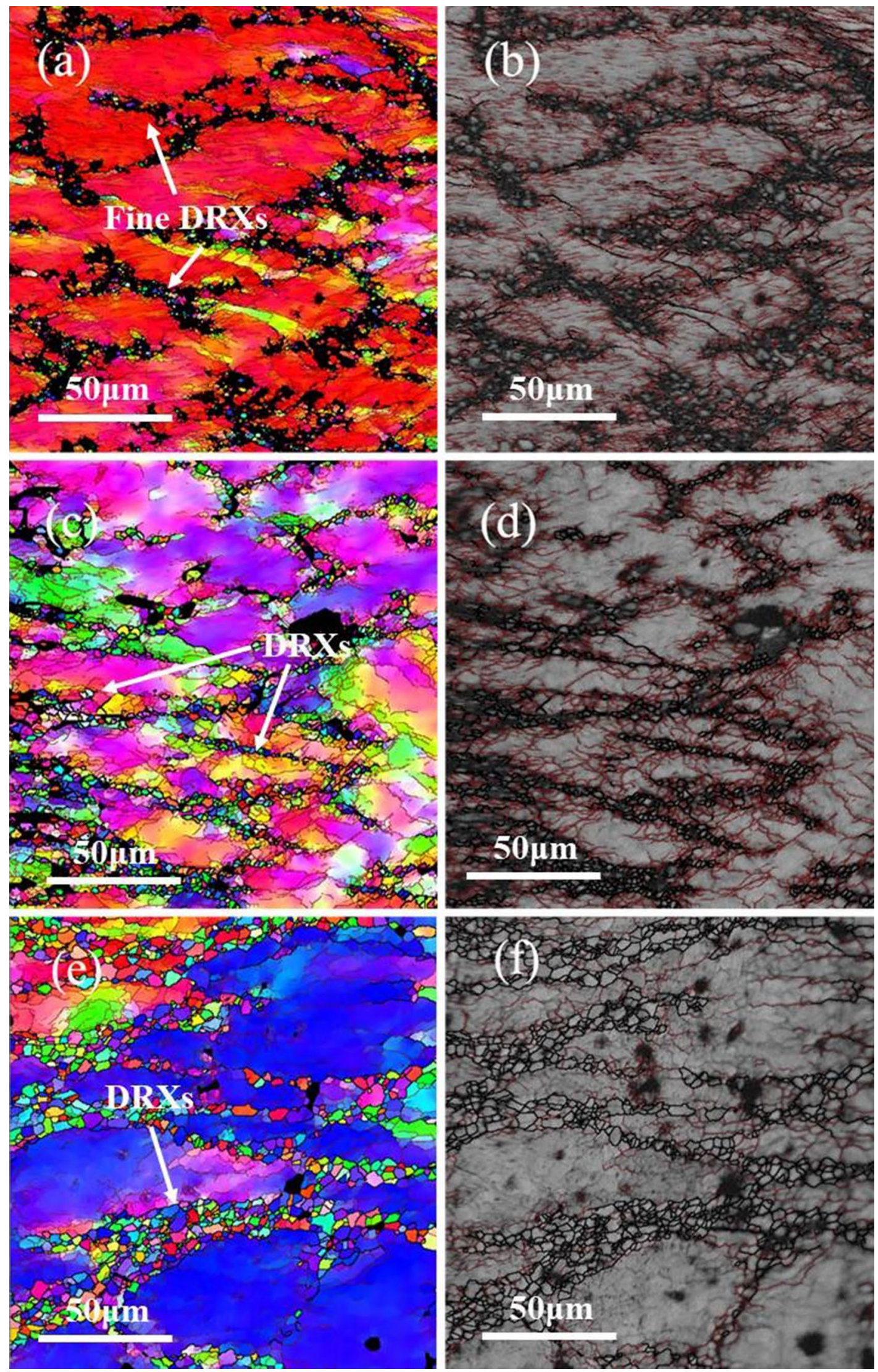
4Fig. 9 EBSD inverse pole figure (IPF) maps and image quality (IQ) maps of the specimens hot-compressed at different conditions: a, b $\ln Z=53.19$ (high $Z, 800{ }^{\circ} \mathrm{C} / 10^{-1} \mathrm{~s}^{-1}$ ); c, d $\ln Z=48.59$ (high $Z$, $800{ }^{\circ} \mathrm{C} / 10^{-3} \mathrm{~s}^{-1}$ ); e, f $\ln Z=39.88$ (low $Z, 1000{ }^{\circ} \mathrm{C} / 10^{-3} \mathrm{~s}^{-1}$ ). The fractions of low-angle grain boundaries of $\mathbf{a}, \mathbf{b}, \mathbf{c}$ are $21,13,5 \%$, respectively

\subsection{The Flow Softening Mechanism}

The samples compressed at high Zener-Hollomon parameter indicate that the microstructures are mainly composed of elongated grains and broken carbides along the grain boundaries (Figs. 6a and 9a). In fcc metals, such as $\mathrm{Cu}$, the stacking-fault energy (SFE) will decrease with increasing content of substitutional solutes [43]. The dislocation activity decreases when the SFE is low; thus, twinning may provide an alternative deformation mechanism to adapt to large strain [44]. However, in the present study there are few twinnings appearing in the microstructure, indicating that cross-slip of dislocations still acts as the main deformation mechanism at high $Z$ condition. Besides, the breakup of initial coarse carbides and DRX takes place at grain boundaries, which can greatly relax internal stress concentration. Additionally, because of lower thermal activation energy and poor atomic diffusion capacity of the matrix, the bonding between the particles and the matrix may be relatively weak. Many voids tend to form during the process when the deformation conditions are unfavorable, as shown in Fig. 6a, thus leading to the deterioration of flowability. Therefore, the cracks can appear easily, which is also responsible for the softening to some extent [45].

With decreasing $Z$ parameter, as shown in Fig. 9e, more DRXed grains appeared at the grain boundaries. In fcc alloys, DRX can be frequently found when the SFE (of $\{111\}$ plane stacking) is low. The reason is that $\{111\}<110>$ dislocations are likely to dissolve into two Shockley partial dislocations when the SFE is low, which possesses mixed nature of edge and screw dislocations. Eleti et al. [46] reported that cross-slip of crew dislocations becomes difficult to occur. As a result, dislocation density increases during deformation, which provides a driving force for recrystallization. Also, it is reported that the diffusion coefficient of individual element in $\mathrm{CoCrFeMnNi}$ is smaller than those of pure fcc metals and $\mathrm{Fe}-\mathrm{Cr}-\mathrm{Ni}(-\mathrm{Si})$ alloys [47]. A low $Z$ condition provides enough energy and time for elements migration, and the process of DRX is much easier. Meanwhile, there are a lot of nano-carbides precipitated inside the grains in the present work, and the DRX nuclei at the vicinities of carbide particles (Fig. 10d). It was also suggested that the higher activation energy can accelerate the formation of particle-stimulated nucleation at lower strain rate and higher deformation temperature [48]. As a result, the particles that stimulate DRX nucleation can be regarded as one of the DRX mechanisms. The higher fraction of DRX grains at low $\mathrm{Z}$ condition may contribute to flow stability and higher power dissipation efficiency [49]. Therefore, DRX is an important deformation mechanism that accounts for the flow softening at low $Z$ condition.

\subsection{Effect of Deformation Conditions on the Hardness of the (CoCrFeMnNi) ${ }_{95} C_{5}$ (at.\%) Alloys}

The increasing hardness of $(\mathrm{CoCrFeMnNi})_{95} \mathrm{C}_{5}$ (at.\%) alloy (Fig. 12) is mainly due to the carbides strengthening and solution strengthening. The carbides are in a form of the coarse particles or nanoprecipitates. It is reported that the contribution to the total of hardness of the $\mathrm{CoCrFeMnNiC}$. 25 alloy by solid solution hardening is relatively small and can be ignored [35]. Thus, the hardness of the present alloy is mainly affected by carbides strengthening, which includes coarse carbide strengthening and fine carbide strengthening. Therefore, the hardness of alloy can be estimated by the following equation [35]:

$$
\begin{aligned}
& \mathrm{HV}_{\text {alloy }}=V_{\text {fcc }} \\
& \left(\mathrm{HV}_{\mathrm{CoCrFeMnNi}}+0.538 G b\left(\frac{\sqrt{f}}{d}\right) \ln \left(\frac{d}{2 b}\right)\right) \\
& +V_{\mathrm{cc}} \mathrm{HV}_{\mathrm{cc}}
\end{aligned}
$$

where $V_{\text {fcc }}$ and $V_{\text {cc }}$ are the volume fractions of the matrix and coarse carbides, $\mathrm{HV}_{\mathrm{CoCrFeMnNi}}(160 \mathrm{HV})$ and $\mathrm{HV}_{\mathrm{cc}}(900 \mathrm{HV})$ are hardness of the matrix and coarse carbide [35], $G(80 \mathrm{GPa})$ is shear modulus [50], $b(0.254)$ is Burgers vector [50], $f$ is volume fraction of fine carbides and $d$ is the diameter of carbides. The values of these parameters are shown in Table 3.

The experimental hardness values of alloys deformed at different $Z$ conditions and the theoretical values calculated using Eq. (6) are shown in Fig. 12. It can be found that the experimental data agree well with the calculated values. The contribution analysis of different structural components shows that $\mathrm{CoCrFeMnNi}$ matrix provides a much larger part of hardness for $(\mathrm{CoCrFeMnNi})_{95} \mathrm{C}_{5}$ (at.\%) alloy $(45.74 \%-52.08 \%)$. According to calculations, each of $1 \%$ content of coarse carbides contributes $10 \mathrm{HV}$ for hardness increasing, and each $1 \%$ content of fine carbides contributes $13 \mathrm{HV}$ for hardness increasing. The result indicates that the increasing hardness of $\mathrm{CoCrFeMnNi}$ with a heavy content of carbon is affected by the combined effects of coarse carbide strengthening and fine carbide strengthening, as confirmed by Wang et al. [51]. Combining microstructure analysis in Fig. 6, the highest hardness (345 HV) at high $Z$ condition $\left(800{ }^{\circ} \mathrm{C} / 10^{-1} \mathrm{~s}^{-1}\right)$ can be attributed to the coarse carbides appeared in the matrix. Moreover, with the crushing of coarse carbides, the fine carbides can greatly improve the processing properties of materials at low $Z$ condition 

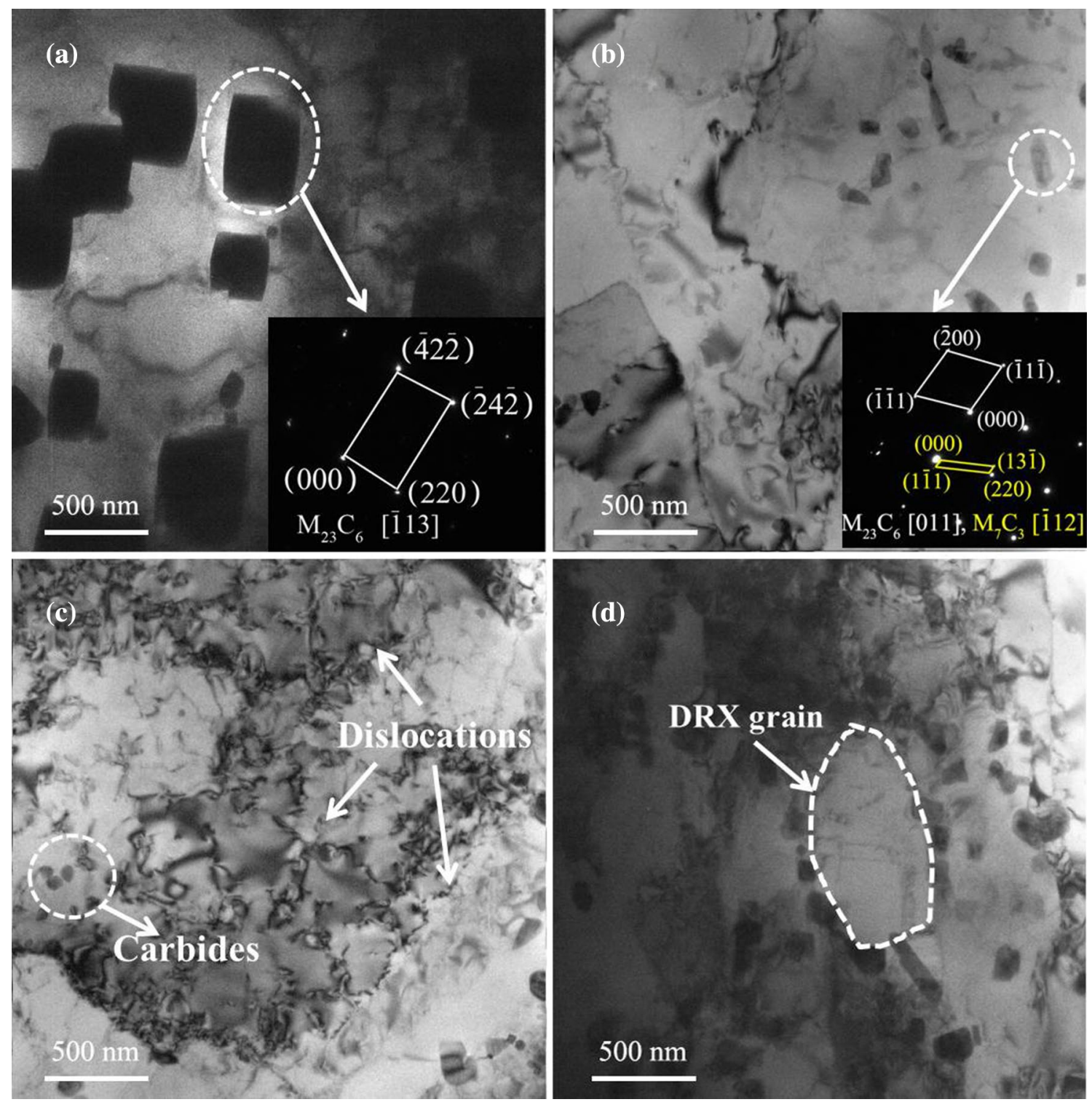

Fig. 10 TEM bright-field images and the selected area electron diffraction patterns (SAEDs) of $(\mathrm{CoCrFeMnNi})_{95} \mathrm{C}_{5}($ at. $\%)$ alloys in $\ln Z=48.59$ (high $Z, 800{ }^{\circ} \mathrm{C} / 10^{-3} \mathrm{~s}^{-1}$ ) a, a $M_{23} \mathrm{C}_{7}$ carbides; $\mathbf{b}-\mathbf{d} \ln Z=39.88$ (low $Z, 1000{ }^{\circ} \mathrm{C} / 10^{-3} \mathrm{~s}^{-1}$ ), b the mixture of $M_{23} \mathrm{C}_{6}$ and $M_{7} \mathrm{C}_{3}$ carbides, $\mathbf{c}$ irregular dislocation cells around the carbides, $\mathbf{d}$ DRX grain in the vicinity of carbide particles

(consistent with the Zhang et al. reported [52]). The determination of optimum condition to obtain a synergy of coarse carbides and fine carbide for excellent hardening mechanism is a subject for further work.

\section{Conclusions}

The hot deformation behavior and microstructure evolution of CoCrFeMnNi-based high-entropy alloy (HEA) with high content of carbon were investigated. Several conclusions are drawn as follows:
1. The estimated apparent activation energy $(Q)$ of $(\mathrm{CoCrFeMnNi})_{95} \mathrm{C}_{5}$ (at.\%) alloy under the hot deformation is calculated to be $423 \mathrm{~kJ} / \mathrm{mol}$. The constitutive equation describes the steady flow stress of $(\mathrm{CoCrFeMnNi})_{95} \mathrm{C}_{5}$ (at.\%) alloy at a true strain of 0.45 and can be determined as:

2. $\dot{\varepsilon}=3.46 \times 10^{19}[\sinh (0.0044 \sigma)]^{6.95} \exp (-423.1 / 8.314 \times T)$

3. A processing map of $(\mathrm{CoCrFeMnNi}){ }_{95} \mathrm{C}_{5}$ (at.\%) alloy was developed to identify the optimum hot deformation conditions, which is found to be at $900-1000{ }^{\circ} \mathrm{C}$ and $10^{-3}-10^{-2.6} \mathrm{~s}^{-1}$. 

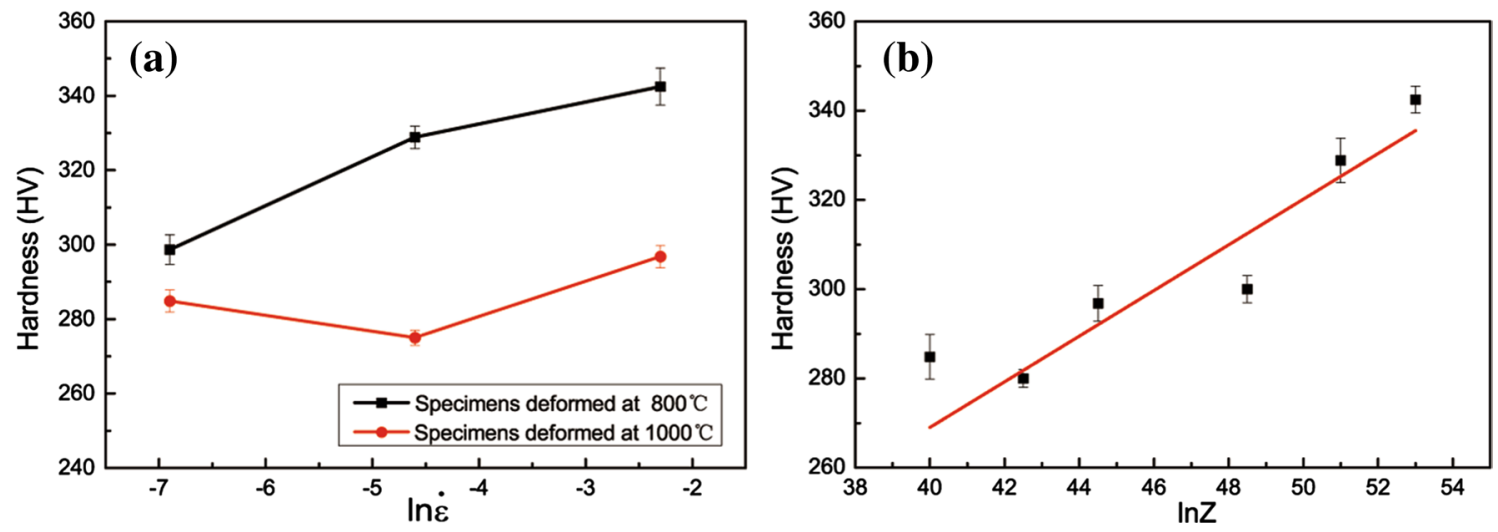

Fig. 11 Hardness of deformed HEAs tested at the room temperature depending on different strain rates a, b various Zener-Hollomon parameters

Table 1 Summary of hardness of CoCrFeNi-based alloys

\begin{tabular}{ll}
\hline Alloy & $\begin{array}{l}\text { Microhard- } \\
\text { ness (HV) }\end{array}$ \\
\hline AlCoCrFeNi (SPS) [37] & 625 \\
CoCrFeNiMn (SPS) [38] & 646 \\
$\mathrm{CoCrFeMnNi} \mathrm{AM})$ [35] & 170 \\
$\mathrm{Al}_{0.5} \mathrm{CoCrCuFeNi}(\mathrm{AM})[36]$ & 208 \\
$(\mathrm{CoCrFeMnNi})_{98} \mathrm{C}_{2}$ (at.\%) (AM) [35] & 240 \\
$(\mathrm{CoCrFeMnNi})_{95} \mathrm{C}_{5}$ (at.\%) (AM) [this work] & 345 \\
\hline
\end{tabular}

Table 2 Activation energy $(Q)$ of alloys based on CoCrFeMnNi

\begin{tabular}{ll}
\hline Alloy & $\begin{array}{l}\text { Activation } \\
\text { energy }(\mathrm{kJ} / \\
\text { mol) }\end{array}$ \\
\hline $\mathrm{CoCrFeMnNi}[40]$ & 350 \\
$(\mathrm{CoCrFeMnNi})_{99} \mathrm{C}_{1}($ at.\%) [31] & 385.43 \\
$(\mathrm{CoCrFeMnNi})_{95} \mathrm{C}_{5}$ (at.\%) [this work] & 423 \\
\hline
\end{tabular}

4. At high Zener-Hollomon parameter, dynamic recrystallization accompanied by dislocation cross-slip at the grain boundaries and breakup of initial coarse carbides can act as the major deformation mechanism. At low Zener-Hollomon parameter, dynamic recrystallization (DRX) becomes an important deformation mechanism that accounts for the flow softening.

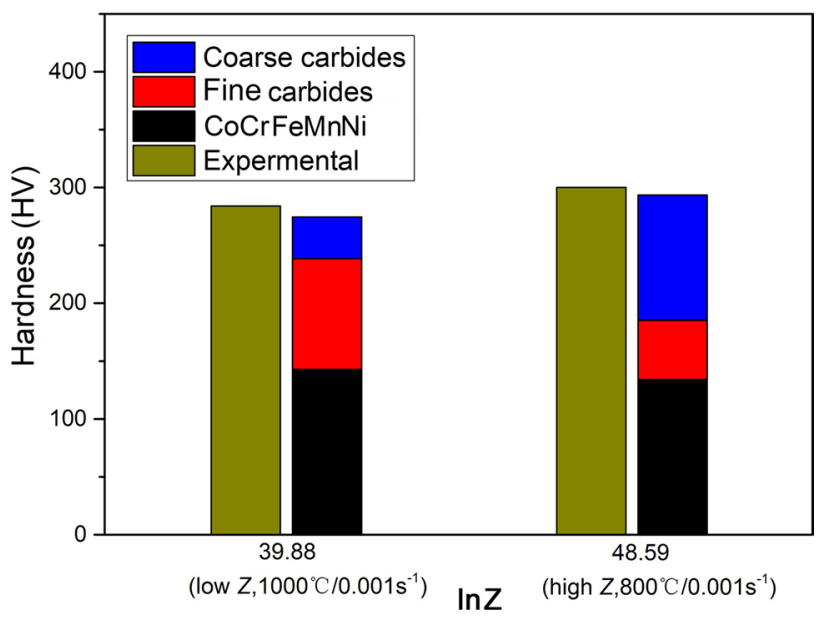

Fig. 12 Comparison between the experimental and calculated values of $(\mathrm{CoCrFeMnNi})_{95} \mathrm{C}_{5}$ (at.\%) alloy hardness at different $Z$ values

5. Many broken coarse carbides can be found in the matrix after being deformed at high $Z$ condition $\left(800{ }^{\circ} \mathrm{C} / 10^{-1}\right.$ $\mathrm{s}^{-1}$ ), which may lead to the highest hardness value of $345 \mathrm{HV}$. With decreasing $Z$ parameter, the volume fraction of fine carbides increases. The increasing hardness of $\mathrm{CoCrFeMnNi}$ with a heavy content of carbon is mainly due to the combined effect of strengthening by both coarse carbides and fine carbides. 
Table 3 Hardness parameters of the $(\mathrm{CoCrFeMnNi})_{95} \mathrm{C}_{5}$ (at.\%) alloy at different $Z$ conditions

\begin{tabular}{lllllllll}
\hline $\begin{array}{l}\text { Zener-Hollomon } \\
\text { parameter }(\ln Z)\end{array}$ & $V_{\mathrm{fcc}}(\%)$ & $\begin{array}{l}\mathrm{HV}_{\mathrm{CoCrFeMnNi}} \\
(\mathrm{HV})[35]\end{array}$ & $G(\mathrm{GPa})[50]$ & $b[50]$ & $\begin{array}{l}f(\text { Fine car- } \\
\text { bides })(\%)\end{array}$ & $d(\mathrm{~nm})$ & $\begin{array}{l}V_{\mathrm{cc}}(\mathrm{Coarse} \\
\text { carbides })(\%)\end{array}$ & $\begin{array}{l}\mathrm{HV} \\
\text { carbides })[35]\end{array}$ \\
\hline 48.59 & 82.68 & 160 & 80 & 0.254 & 4.12 & 250 & 10.44 & 900 \\
39.88 & 89.74 & & & & 7.14 & 150 & 3.09 & \\
\hline
\end{tabular}

Acknowledgements This work was financially supported by the National Natural Science Foundation of China (No. 51601022), the National Key Research and Development plan of China (No. 2016YFB0700302) and the Science and Technology Planning Project of Hunan Province of China (No. 2015SK1002-1).

\section{References}

[1] K. Fukaura, Y. Yokoyama, D. Yokoi, N. Tsujii, K. Ono, Metall. Mater. Trans. A 35, 1289 (2004)

[2] I. Picas, N. Cuadrado, D. Casellas, A. Goez, L. Llanes, in Fatigue 2010, ed. by P. Lukas (Elsevier Science Bv, Amsterdam, 2010), p. 1777

[3] J.W. Yeh, S.K. Chen, S.J. Lin, J.Y. Gan, T.S. Chin, T.T. Shun, C.H. Tsau, S.Y. Chang, Adv. Eng. Mater. 6, 299 (2004)

[4] C.J. Tong, Y.L. Chen, J.W. Yeh, S.J. Lin, S.K. Chen, T.T. Shun, C.H. Tsau, S.Y. Chang, Metall. Mater. Trans. A 36, 881 (2005)

[5] J.W. Yeh, S.Y. Chang, Y.D. Hong, S.K. Chen, S.J. Lin, Mater. Chem. Phys. 103, 41 (2007)

[6] A. Li, X. Zhang, Acta Metall. Sin. (Engl. Lett.) 22, 219 (2009)

[7] X. Yang, X. Wang, X. Ling, D. Wang, Results Phys. 7, 1412 (2017)

[8] B. Gludovatz, A. Hohenwarter, D. Catoor, E.H. Chang, E.P. George, R.O. Ritchie, Science 345, 1153 (2014)

[9] H. Shahmir, T. Mousavi, J. He, Z. Lu, M. Kawasaki, T.G. Langdon, Mater. Sci. Eng. A 705, 411 (2017)

[10] X.L. Shang, Z.J. Wang, Q.F. Wu, J.C. Wang, J.J. Li, J.K. Yu, Acta Metall. Sin. (Engl. Lett.) 32, 41 (2019)

[11] Y. Lu, H. Huang, X. Gao, C. Ren, J. Gao, H. Zhang, S. Zheng, Q. Jin, Y. Zhao, C. Lu, T. Wang, T. Li, J. Mater. Sci. Technol. 35, 369 (2019)

[12] B. Zhang, Y. Zhang, S. Guo, J. Mater. Sci. 53, 14729 (2018)

[13] W. Li, P.K. Liaw, Y. Gao, Intermetallics 99, 69 (2018)

[14] Y.Z. Tian, S.J. Sun, H.R. Lin, Z.F. Zhang, J. Mater. Sci. Technol. 35, 334 (2019)

[15] S.G. Ma, Y. Zhang, Mater. Sci. Eng. A 532, 480 (2012)

[16] C.Y. Hsu, J.W. Yeh, S.K. Chen, T.T. Shun, Metall. Mater. Trans. A 35, 1465 (2004)

[17] A. Zaddach, R. Scattergood, C. Koch, Mater. Sci. Eng. A 636, 373 (2015)

[18] H. Zuhailawati, T.C. Geok, P. Basu, Mater. Des. 31, 2211 (2010)

[19] S. Kang, Y.S. Jung, J.H. Jun, Y.K. Lee, Mater. Sci. Eng. A 527, $745(2010)$

[20] S. Fang, W. Chen, Z. Fu, Mater. Des. 54, 973 (2014)

[21] J.M. Zhu, H.M. Fu, H.F. Zhang, A.M. Wang, H. Li, Z.Q. Hu, J. Alloys Compd. 509, 3476 (2011)

[22] T.D. Huang, L. Jiang, C.L. Zhang, H. Jiang, Y.P. Lu, T.J. Li, Sci. China Technol. Sci. 61, 117 (2018)

[23] Z. Wu, C.M. Parish, H. Bei, J. Alloys Compd. 647, 815 (2015)

[24] J.Y. He, H. Wang, H.L. Huang, X.D. Xu, M.W. Chen, Y. Wu, X.J. Liu, T.G. Nieh, K. An, Z.P. Lu, Acta Mater. 102, 187 (2016)
[25] L.B. Chen, R. Wei, K. Tang, J. Zhang, F. Jiang, L. He, J. Sun, Mater. Sci. Eng. A 716, 150 (2018)

[26] S. Orhan, A.O. Er, N. Camuşcu, E. Aslan, NDT E Int. 40, 121 (2007)

[27] N. Camuşcu, E. Aslan, J. Mater. Process. Technol. 170, 121 (2005)

[28] E.O. Ezugwu, Z.M. Wang, A.R. Machado, J. Mater. Process. Technol. 86, 1 (1999)

[29] X. Qin, D. Huang, X. Yan, X. Zhang, M. Qi, S. Yue, J. Alloys Compd. 770, 507 (2019)

[30] M. Saadati, R.A. Khosroshahi, G. Ebrahimi, M. Jahazi, Mater. Charact. 131, 234 (2017)

[31] J. Li, B. Gao, S. Tang, B. Liu, Y. Liu, Y. Wang, J. Wang, J. Alloys Compd. 747, 571 (2018)

[32] C. Zener, J.H. Hollomon, J. Appl. Phys. 15, 22 (1944)

[33] N.R. Jaladurgam, A.K. Kanjarla, Mater. Sci. Eng. A 712, 240 (2018)

[34] F. Kong, Y. Chen, D. Zhang, S. Zhang, Mater. Sci. Eng. A 539, 107 (2012)

[35] N.D. Stepanov, N.Y. Yurchenko, M.A. Tikhonovsky, G.A. Salishchev, J. Alloys Compd. 687, 59 (2016)

[36] C.C. Tung, J.W. Yeh, T.T. Shun, S.K. Chen, Y.S. Huang, H.C. Chen, Mater. Lett. 61, 1 (2007)

[37] W. Ji, Z. Fu, W. Wang, H. Wang, J. Zhang, Y. Wang, F. Zhang, J. Alloys Compd. 589, 61 (2014)

[38] W. Ji, W. Wang, H. Wang, J. Zhang, Y. Wang, F. Zhang, Z. Fu, Intermetallics 56, 24 (2015)

[39] S. Liu, Q. Pan, H. Li, Z. Huang, K. Li, X. He, X. Li, J. Mater. Sci. 54, 1 (2019)

[40] N. Stepanov, M. Tikhonovsky, N. Yurchenko, D. Zyabkin, M. Klimova, S. Zherebtsov, A. Efimov, G. Salishchev, Intermetallics 59, 8 (2015)

[41] G. Qin, R. Chen, H. Zheng, H. Fang, L. Wang, Y. Su, J. Guo, H. Fu, J. Mater. Sci. Technol. 35, 578 (2019)

[42] Z. Wang, Q. Fang, J. Li, B. Liu, Y. Liu, J. Mater. Sci. Technol. 34, 349 (2018)

[43] K. Evans, Treatise on Materials Science \& Technology (Elsevier, Amsterdam, 1974), p. 113

[44] B. Liu, J. Wang, Y. Liu, Q. Fang, Y. Wu, S. Chen, C.T. Liu, Intermetallics 75, 25 (2016)

[45] S. Chen, D. Fu, H. Luo, Y. Wang, J. Teng, H. Zhang, Vacuum 149, 297 (2018)

[46] R.R. Eleti, T. Bhattacharjee, L. Zhao, P.P. Bhattacharjee, N. Tsuji, Mater. Chem. Phys. 210, 176 (2018)

[47] K.Y. Tsai, M.H. Tsai, J.W. Yeh, Acta Mater. 61, 4887 (2013)

[48] S. Jiang, Y. Zhang, S. Wang, C. Zhao, J. Mater. Sci. 52, 3199 (2017)

[49] T.Y. Kwak, W.J. Kim, J. Mater. Sci. Technol. 35, 181 (2019)

[50] G. Laplanche, P. Gadaud, O. Horst, F. Otto, G. Eggeler, E. George, J. Alloys Compd. 623, 348 (2015)

[51] Z. Wang, I. Baker, W. Guo, J.D. Poplawsky, Acta Mater. 126, 346 (2017)

[52] S. Zhang, W. Zeng, X. Gao, D. Zhou, Y. Lai, J. Alloys Compd. 684, 201 (2016) 